\title{
Norovirus Extraction from Frozen Raspberries Using Magnetic Silica Beads
}

\author{
Philippe Raymond ${ }^{1}$ (D) Sylvianne Paul ${ }^{1} \cdot$ André Perron $^{1} \cdot$ Louise Deschênes $^{2}$
}

Received: 12 November 2020 / Accepted: 6 February 2021 / Published online: 2 March 2021

(c) Crown 2021

\begin{abstract}
Human noroviruses $(\mathrm{HuNoV})$ are among the main causes of acute gastroenteritis worldwide. Frozen raspberries have been linked to several HuNoV food-related outbreaks. However, the extraction of HuNoV RNA from frozen raspberries remains challenging. Recovery yields are low, and real-time quantitative reverse transcriptase PCR (RT-qPCR) inhibitors limit the sensitivity of the detection methodologies. A new approach using fine magnetic silica beads was developed for the extraction of HuNoV spiked on frozen raspberries. Relatively low recovery yields were observed with both the magnetic silica bead and the reference ISO 15216-1:2017 methods. High RT-qPCR inhibition was observed with the ISO 15216-1:2017 recommended amplification kit but could be reduced by using an alternative kit. Reducing RT-qPCR inhibition is important to limit the number of inconclusive $\mathrm{HuNoV}$ assays thus increasing the capacity to assess the HuNoV prevalence in frozen raspberries.
\end{abstract}

Keywords Norovirus $\cdot$ Raspberries $\cdot$ RNA extraction $\cdot$ Silica $\cdot$ RT-qPCR

\section{Introduction}

Human Norovirus (HuNoV) is one of the leading causes of food-related illnesses in developed countries. HuNoV represents $58 \%$ of all reported foodborne outbreaks of known etiology in the United States (Vinje 2015). About 300-400 outbreaks of HuNoV are reported to the National Enteric Surveillance Program of the Public Health Agency of Canada each year (Government of Canada 2018). Forty-six berry outbreaks associated to $\mathrm{HuNoV}$ contamination with 15,827 cases were reported globally between 1983 and 2018 (Bozkurt et al. 2020). In the European Union, contaminated frozen red fruits were shown to represent an important cause of HuNoV outbreaks (Boqvist et al. 2018). Contaminated frozen raspberries are the most common sources (Bozkurt et al. 2020). Frozen raspberries were implicated as food vehicles in 33 of the 40 reported outbreak events associated

Philippe Raymond

philippe.raymond@canada.ca

1 Canadian Food Inspection Laboratory (CFIA), St. Hyacinthe Laboratory, Food Virology, Saint Hyacinthe, QC, Canada

2 Agriculture and Agri-Food Canada (AAFC), St. Hyacinthe Research and Development Centre, Saint Hyacinthe, QC, Canada with contaminated frozen product between 2008 and 2018 (Nasheri et al. 2019).

Noroviruses are small (27-40 nm) non-enveloped singlestranded RNA viruses that are transmitted mainly via the fecal-oral route. Noroviruses belong to a genetically diverse group of viruses of the Caliciviridae family. There are 10 distinct norovirus genetic groups (Chhabra et al. 2019). HuNoV GI and GII are the most prevalent genogroups associated with outbreaks. Noroviruses can persist in an infectious state for prolonged periods of time in the environment, in water, and in food (reviewed in Cook et al. (2016)). They can also withstand a broad $\mathrm{pH}$ range ( $\mathrm{pH} 2-9)$. In cold temperatures, noroviruses can stay infectious for years. However, they are inactivated by cooking. The greatest risk of a foodborne $\mathrm{HuNoV}$ infection arises from the consumption of contaminated food such as fresh or frozen fruits, leafy vegetables, oysters, and drinking water.

Detection of HuNoV relies on the extraction of RNA and real-time reverse transcriptase PCR amplification methodologies (Vinje 2015). Prior to detection, minute amounts of viruses must be extracted from food matrices. Methods for concentrating noroviruses extracted from contaminated food are based mainly on ultrafiltration, ultracentrifugation, cationic separation, and polyethylene glycol (PEG) precipitation. These methods are associated with high variability and relatively low recovery of HuNoV (Summa and Maunula 
2018). The ISO/TS 15216-1:2013 technical specification and the subsequent ISO 15216-1:2017 standard were published to provide a reference method for the quantitative extraction and detection of $\mathrm{HuNoV}$ from various food products. The extraction from soft fruit, leaf, stem, and bulb vegetables is based on PEG precipitation of the virus. However, PCR inhibitors are frequently reported when PEG-based approaches are applied to soft fruits and can lead to falsenegative results (Summa and Maunula 2018). PCR inhibitors are also reported when using ultrafiltration, Cat-Floc precipitation, and immunomagnetic bead-based extraction methods as well, reducing the norovirus recovery yields substantially (Summa et al. 2012). Extraction methods with low recovery yields increase the probability of false-negative results. Assays with more than $75 \%$ real-time quantitative reverse transcriptase PCR (RT-qPCR) inhibition should be considered inconclusive (ISO 2017).

Other groups have used cationic beads or filters at high $\mathrm{pH}$ for norovirus adsorption and elution and have had various success rates (Morales-Rayas et al. 2010; Scherer et al. 2010; Stals et al. 2012). The recombinant HuNoV capsid protein VPI isoelectric point was reported to be $\mathrm{pH} 5$ (Da Silva et al. 2011). Accordingly, norovirus should be positively charged below its capsid isoelectric point. Relatively high recovery yields (68\%) for HuNoV GII from wastewater were reported using celite, a siliceous rock powder, at pH 4 (Brinkman et al. 2013). Silica surfaces are covered by silanol groups which can exist in different states. From previous studies, it is expected that crystalline and vitreous silica surfaces should maintain a negative charge above $\mathrm{pH}$ 2 and 3, respectively (Júnior and Baldo 2014). Andrade et al. (2009) reported an isoelectric point of 2.3 for silica-coated magnetic beads in suspension in $\mathrm{KCl} 1 \mathrm{mM}$.

In this study, we present the performance of a new magnetic silica bead (MSB) methodology for the extraction of norovirus. We compared the performance of this approach to the ISO 15216-1:2017 method with a focus on the RT-qPCR inhibition associated to the extraction and detection. Reducing RT-qPCR inhibition is important to limit the number of inconclusive assays.

\section{Methods}

\section{Virus Stocks}

Murine norovirus-1 (MNV) was provided by Dr. H. Virgin from Washington University (St. Louis, MO, USA). MNV was propagated in the RAW 264.7 cell line as previously described and viral stocks were titrated by plaque assays (Gonzalez-Hernandez et al. 2012). HuNoV-positive stool samples HuNoV GI.5 (CFIA-FVR-022) and GII.4 (CFIAFVR-019) were provided by the British Columbia Center for Disease Control (BCCDC). The preparation of $\mathrm{HuNoV}$ from clarified $10 \%$ stool samples was adapted from Houde et al. (2006). Briefly, the stool samples were diluted in $1 \times$ phosphate-buffered saline (PBS), pH 7.4 (Gibco, Canada) to obtain a $10 \%$ suspension and were homogenized by vigorous agitation. Suspensions were clarified by centrifugation $\left(20,000 \times g, 15 \mathrm{~min}, 4^{\circ} \mathrm{C}\right)$ and kept frozen at $-80^{\circ} \mathrm{C}$.

\section{Frozen Raspberry Samples}

Frozen raspberries, from bags labeled as whole individually quick frozen (IQF) collected at local stores, were subdivided in $25 \mathrm{~g}$ samples and used for artificial contamination experiments.

\section{Artificial Contamination of Frozen Raspberries}

Aliquots of clarified $10 \%$ stools of $\mathrm{HuNoV}$ were vortexed for $2 \mathrm{~s}$ and diluted in PBS to the genomic equivalent copy (gEq) level needed in $100 \mu \mathrm{l}$ per sample. To estimate the recovery yields, between $10^{3}$ and $10^{6} \mathrm{gEq}$ of HuNoV GI.5, GII.4, and $\mathrm{MNV}$ were inoculated. To estimate the recovery yields in the presence of a competitor strain, $10^{5} \mathrm{gEq} \mathrm{HuNoV} \mathrm{GII.4} \mathrm{and}$ $10^{5} \mathrm{gEq}$ GI.5 were inoculated simultaneously. To estimate the limit of detection (LOD), the HuNoV GII.4 stocks were serially diluted to $10^{5}-10^{2} \mathrm{gEq}$ per $100 \mu \mathrm{l}$.

Frozen raspberries were spiked with the diluted viral suspensions on the surface of the food matrices $(25 \mathrm{~g})$ in a Whirl-Pak ${ }^{\circledR}$ filter bag (VWR, Canada), then left to air dry $30 \mathrm{~min}$ in a biosafety cabinet. A frozen raspberries sample, with no virus added, was included in each extraction batch as a negative control. The amount of virus in the $100 \mu \mathrm{l}$ inoculum was assessed in parallel by extracting the total RNA using the RNeasy kit (QIAGEN) followed by a RT-qPCR assay as described below.

\section{Virus Elution and RNA Extraction}

Viral RNA was extracted from frozen raspberries using the MSB method by proceeding with the following steps (Fig. 1):

Step 1 The virus was eluted from the matrix by adding $40 \mathrm{ml}$ of elution buffer made of $150 \mathrm{mM}$ Bis-Tris-Propane (Sigma-Aldrich, Canada) $\mathrm{pH} 8$ to the sample in the filter bag then closing the bag and shaking it at about 55 RPM for $30 \mathrm{~min}$ at room temperature (RT) using an orbital shaker. Using a $25 \mathrm{ml}$ borosilicate glass pipet, the eluate was transferred to a 50-ml conical centrifuges tubes.

Step 2 The eluate was clarified by centrifugation at $3500 \times \mathrm{g}$ for $10 \mathrm{~min}$. Thirty units of Aspergillus niger pectinase (Sigma-Aldrich) were added to the clarified eluate followed by a $30 \mathrm{~min}$ incubation at $37{ }^{\circ} \mathrm{C}$ with shaking at approximately 70 RPM. Meanwhile, a volume of $100 \mu \mathrm{l}$ per 


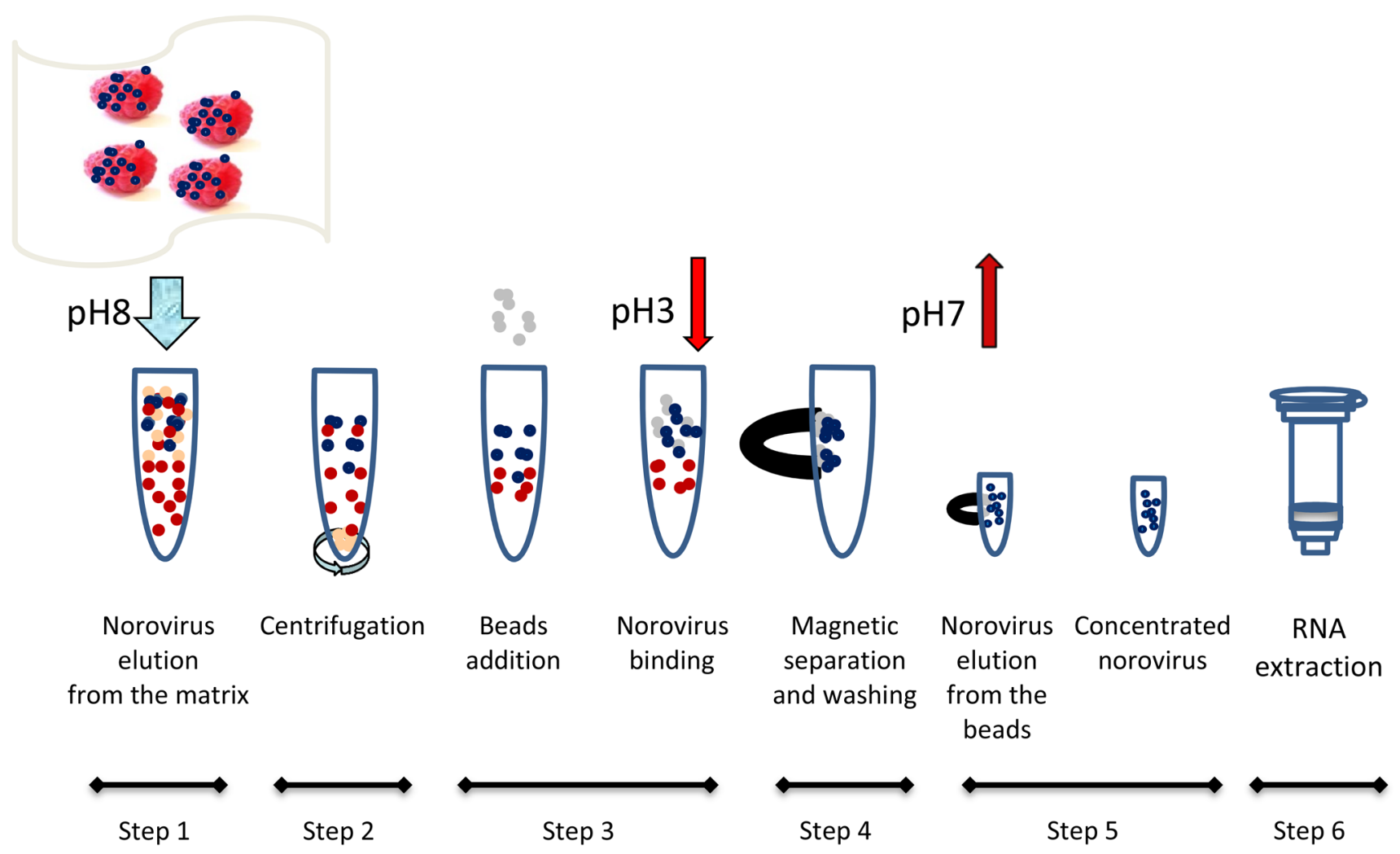

Fig. 1 Norovirus extraction and concentration method using the magnetic silica beads (MSB) approach. Viruses (blue dots) are purified from matrix and soil contaminants (brown and red dots) using magnetic silica beads (gray dots) prior to the RNA extraction

sample of AccuNanobeads (Bioneer, CA, USA, average size range 300-700 nm) was vortexed for $3 \mathrm{~min}$. The AccuNanobeads storage buffer was removed using a magnet, and the beads were resuspended in $1 \mathrm{ml}$ per sample of the elution buffer containing $100 \mu \mathrm{g} / \mathrm{ml}$ Pluronic F-127 (Anatrace, OH, USA) and vortexed for a few seconds.

Step 3 The bead suspension was added to the clarified eluate and vortexed $3 \mathrm{~s}$. Two milliliters of $200 \mathrm{mM}$ ascorbic acid (Sigma-Aldrich) and $3.5 \mathrm{ml}$ of $200 \mathrm{mM}$ malic acid (Sigma-Aldrich) were added to each sample, and the tubes were vortexed another $3 \mathrm{~s}$. The $\mathrm{pH}$ was lowered between $\mathrm{pH}$ 2 and 3 with the addition of approximately $850 \mu$ of $6 \mathrm{~N}$ $\mathrm{HCl}$. The tubes were then mixed using a Dynal rotary shaker 94701 (Thermo Fisher, Canada) set between 19 and 22, for 10 to $60 \mathrm{~min}$ at RT.

Step 4 The solution was separated from the beads using a magnetic rack and removed by decantation. The remaining beads were washed with $1 \mathrm{ml}$ of washing buffer composed of $17.4 \mathrm{mM}$ Bis-Tris-Propane buffer pH 7 with $8.7 \mathrm{mM} \mathrm{NaCl}$, $0.87 \mathrm{mM} \mathrm{CaCl}_{2}, 10.9 \mathrm{mM}$ ascorbic acid, and $15.2 \mathrm{mM}$ malic acid.

Step 5 The viruses were eluted twice from the beads with $100 \mu \mathrm{l}$ of the bead elution buffer composed of $45 \mathrm{mM}$ Bis-Tris-propane $\mathrm{pH} \mathrm{9,0.01 \%} \mathrm{Tween} \mathrm{20,} \mathrm{and} 50 \mathrm{mM}$ EDTA (Sigma-Aldrich). Beads were vortexed $3 \mathrm{~s}$ with the elution buffer. The first and second elutions were performed by agitation at about 1050 RPM in a Thermomixer R (Eppendorf, Canada) at RT for $10 \mathrm{~min}$ and $1 \mathrm{~min}$, respectively. Virus eluates were immediately transferred to a $1.5 \mathrm{ml}$ microtube and combined with $500 \mu \mathrm{l}$ buffer RLT plus $\beta$-mercaptoethanol from the RNeasy QIAcube kit (QIAGEN) or $10 \mu \mathrm{l}$ of $2 \mathrm{M}$ Dithiothreitol (SigmaAldrich). Five microliters of RNA carrier $(1 \mu \mathrm{g} / \mathrm{ml})$ (QIAGEN) and $140 \mu$ l of the polyvinylpolypyrrolidone (PVPP; Sigma-Aldrich) suspension (2\% v/v final) were added to each sample, and the samples were vortexed briefly. Samples were centrifuged at $10,000 \times g$ minimum for $5 \mathrm{~min}$ to remove the PVPP.

Step 6 Total RNA was extracted using the RNeasy QIAcube kit supplemented with DNase I in the QIAcube platform as described by the manufacturer (QIAGEN). The RNA was eluted from the spin column membrane with $50 \mu \mathrm{l}$ of RNase-free water from the kit to which 40 units of the RNasin Plus RNase inhibitor (Fisher Scientific, Canada) were added. It was then stored at $-80{ }^{\circ} \mathrm{C}$.

As a reference method, the ISO 15216-1:2017 method for soft fruit samples (ISO 2017) was also used for the extraction of the viruses from spiked frozen raspberries. The pectinase from Aspergillus aculeatus (1140 U) was used. The NucliSens miniMAG kit (Biomérieux, Canada) was used to 
extract RNA in $50 \mu$ elution buffer following the manufacturer's recommendations.

\section{RT-qPCR}

RT-qPCR assays were performed using $5 \mu$ l of diluted (1/10) or non-diluted RNA extracts, using either the Mx3005P system (Stratagene, CA, USA) or the Quantstudio 6 system (Thermo Fisher). Diluted RNA extracts were prepared using RNase-free water. Unless otherwise specified, HuNoV GII RT-qPCR was performed using QNIF2d and COG2R primers and the probe QNIFS (Table1) following the procedure described in ISO 15216-1:2017 (ISO 2017). HuNoV GI RTqPCR was performed using QNIF4 and NV1LCR primers (Da Silva et al. 2007; Svraka et al. 2007) with the TM9 probes (Hoehne and Schreier 2006). MNV detection was performed based on RT-qPCR ORF1/ORF2 primer system developed by Baert et al. (2008). In both cases, $5 \mu \mathrm{l}$ from the RNA extracts were tested using the TaqMan Fast Virus 1-Step Master Mix (Thermo Fisher). The reverse transcription was performed at $50{ }^{\circ} \mathrm{C}$ for $20 \mathrm{~min}$, and the amplification profile included $20 \mathrm{~s}$ at $95{ }^{\circ} \mathrm{C}$, and 45 cycles of $3 \mathrm{~s}$ at $95^{\circ} \mathrm{C}$ and $30 \mathrm{~s}$ at $60^{\circ} \mathrm{C}$.

Virus gEq quantification was determined using standard curves generated with in vitro RNA transcripts containing target sequences for HuNoV GI, GII, or MNV with small sequence inserts to differentiate them from the circulating strains. The HuNoV GII RNA transcript UV concentration was divided by a correction factor of 1.8, established by droplet digital PCR (ddPCR) (Advance Analysis Centre Guelph University, Canada). Briefly, reverse transcriptase reactions were performed in triplicate as described above using the COG2R primer. The Automated Droplet Generator (Bio-Rad, Canada) was used to generate droplets.
QPCRs were performed as described below using the C1000 touch Thermal cycler and ddPCR Multiple Supermix (BioRad). Plates were read using the QX200 Droplet Reader (Bio-Rad).

\section{Recovery Yield Calculation}

The recovery yields associated with the virus elution and concentration steps were estimated using the cycle thresholds $(\mathrm{Ct})$ variation. The virus recovery yields $=10^{(\Delta C \mathrm{t} / \mathrm{m})} \times 100 \%$, where $\Delta C_{t}=C t_{\text {matrix }}-C t_{\text {inoculum }}$ is the $C t_{\text {matrix }}$ value of extracted viral RNA from the matrix minus the $C t_{\text {inoculum }}$ value of viral RNA extracted from the inoculum, and $m$ is the slope of the virus RNA transcript standard curve.

For the MSB method, the inoculum viral RNA levels were estimated from the extraction of $100 \mu \mathrm{l}$ of the virus diluted with $100 \mu$ l of the bead elution buffer using the RNeasy Qiacube kit and its analysis by RT-qPCR.

For the ISO 15216-1:2017 method, the inoculum viral RNA levels were estimated from the extraction of $100 \mu \mathrm{l}$ of the virus dilution using the NucliSens miniMAG kit and its analysis by RT-qPCR.

\section{RT-qPCR Inhibition}

The RT-qPCR inhibition from the matrix was evaluated as recommended in ISO 15216-1:2017 using RNA transcripts with insert as an external amplification control (EAC). Briefly, non-spiked raspberry samples were extracted using the MSB or the ISO 15216-1:2017 protocol as described above. Five microliter of RNA extract was spiked with 625 gEq of EAC and tested by RT-qPCR using either the RNA UltraSense or the TaqMan Fast Virus 1-Step Master Mix kit

Table 1 Primers, probes, and RNA transcripts used in this study

\begin{tabular}{llll}
\hline Methods & Primer or probe & Sequence 5'-3' & References \\
\hline $\begin{array}{l}\text { Norovirus GI } \\
\text { RT-qPCR, qPCR }\end{array}$ & QNIF4 & CGC TGG ATG CGN TTC CAT & Da Silva et al. (2007) \\
RT-qPCR, qPCR & NV1LCR & CCT TAG ACG CCA TCA TCA TTT AC & Svraka et al. (2007) \\
RT-qPCR, qPCR & FAM-TM9-MGBNFQ & TGG ACA GGA GAT CGC & Hoehne and Schreier (2006) \\
PCR & GISKR & CTG CCC GAA TTY GTA AAT GA & Kojima et al. (2002) \\
PCR & GISKF & CCA ACC CAR CCA TTR TAC A & Kojima et al. (2002) \\
Norovirus GII & & & Loisy et al. (2005) \\
RT-qPCR, qPCR & QNIF2d & ATG TTC AGR TGG ATG AGR TTC TCW GA & Loisy et al. (2005) \\
RT-qPCR, qPCR & FAM-QNIFS-BHQ-1 & AGC ACG TGG GAG GGC GAT CG & Kageyama et al. (2003) \\
RT-qPCR, qPCR & COG2R & TCG ACG CCA TCT TCA TTC ACA & Baert et al. (2008) \\
Murine norovirus & & & Baert et al. (2008) \\
RT-qPCR & FW-ORF1/ORF2 & CAC GCC ACC GAT CTG TTC TG & Baert et al. (2008) \\
RT-qPCR & RV-ORF1/ORF2 & GCG CTG CGC CAT CAC TC & CGC TTT GGA ACA ATG \\
RT-qPCR & FAM-ORF1/ORF2-MGBNFQ & C & \\
\hline
\end{tabular}


as described above. EAC spiked in RNase-free water was used as controls.

RT-qPCR inhibition rate $=\left(1-10^{(\Delta C t / m)}\right) \times 100 \%$ where $\Delta C_{t}=C t_{\text {matrix }}-C t_{\text {water }}$ is the $C t_{\text {matrix }}$ value of RNA transcript spiked in RNA extracted from the matrix minus $C t_{\text {water }}$ value of RNA transcript in water and $m$ is the slope of the virus transcript RNA standard curve.

\section{Limit of Detection (LOD) Calculation}

The PODLOD program (v9) (Wilrich and Wilrich 2009) was used to calculate the $\mathrm{LOD}_{50}$ and $\mathrm{LOD}_{95}$.

\section{Statistical Analyses}

Unless otherwise specified, all statistical analyses were performed on log-transformed values using the independent samples $t$ test $(p>0.05)$. The F-test was performed to evaluate the variance. A two-way analysis of variance (ANOVA) with the Bonferroni statistical correction was used to evaluate the impact of the extraction and detection method on the RT-qPCR inhibition $(p>0.05)$ (MedCalc 17.5.5).

\section{Results}

\section{Recovery Yields}

The performance of the MSB method was evaluated by assessing its recovery yields in comparison to the ISO 15216-1:2017 method using IQF frozen raspberries spiked with HuNoV GII.4, GI.5, or MNV (Table 2). In our laboratory setting, the virus elution and concentration methods for norovirus using the MSB had a turnaround time of approximately $7 \mathrm{~h}$, including $1 \mathrm{~h}$ required for the robotic RNA extraction. The ISO 15216-1:2017 method had a turnaround time of $9 \mathrm{~h}$, including the inoculation and the manual NucliSens miniMAG RNA extraction performed on the second day. We had some difficulty resuspending the pellet after the PEG precipitation step when 30 units of pectinase from A. niger were used as indicated in the ISO/ TS 15216-1:2013 (data not shown). When the pectinase from A. aculeatus was used as indicated as an alternative in the ISO 15216-1:2017 protocol version, the pellet was resuspended more easily. Nevertheless, the $\mathrm{HuNoV}$ GII.4 recovery yields from frozen raspberries using the MSB and ISO 15216-1:2017 methods were not statistically different $(p=0.366)$ and were $2.6 \%$ and $1.8 \%$, respectively. When high $\left(5 \times 10^{4} \mathrm{gEq}\right)$ or low amounts of viruses $\left(1.7 \times 10^{3} \mathrm{gEq}\right)$ were spiked and extracted using the MSB method, the HuNoV GII.4 recovery yields were again not statistically different $(p=0.855)$. Recovery yields for HuNoV GI.5 were similar to HuNoV GII and calculated to be $3.6 \%$. Repeated freezing and thawing of raspberry matrices before the virus elution appeared to release more pectin and/or the formation of agglomerates that precluded the magnetic beads handling. Consequently, frozen raspberry matrices were classified as unfit if they had been received thawed and were not used to evaluate recovery yields.

As for MNV, the recovery yield from spiked frozen raspberries using the MSB method was $2.8 \%$, similar to the HuNoV GI and GII recovery yields (One-way ANOVA, $p=0.431)$. The tissue culture infectious dose $\left(\mathrm{TCID}_{50}\right)$ of the MNV production batch was titrated at $203 \mathrm{gEq} /$ $\mathrm{TCID}_{50}(\mathrm{CI} 95 \% 139-297 ; n=7)$. With a recovery yield of $2.8 \%$ using MSB, it was extrapolated that $25 \mathrm{~g}$ of frozen raspberries spiked with $100 \mu \mathrm{l}$ of a MNV at $53 \mathrm{TCID}_{50} /$ $\mathrm{ml}$ should allow $3 \mathrm{MNV}$ genomic copies in the RT-qPCR tubes to be detected $94 \%$ of the time according to the Poisson distribution.

Moreover, the addition of a competitor strain did not have any impact on norovirus recovery yields from spiked frozen raspberries using the MSB method. Indeed, the HuNoV GII recovery yields in the presence or absence of HuNov GI.5 were in the same range $3.4 \%$ and $4.5 \%$, respectively ( $p=0.247)$ (Table 3 ).
Table 2 Detection of norovirus in spiked frozen raspberries

\begin{tabular}{|c|c|c|c|c|c|c|c|}
\hline \multirow[t]{2}{*}{ Extraction method } & \multirow[t]{2}{*}{ Virus } & \multirow[t]{2}{*}{ Spiking level ${ }^{\mathrm{a}}$} & \multirow[t]{2}{*}{$n$} & \multicolumn{2}{|l|}{ Undiluted } & \multicolumn{2}{|c|}{ Diluted (1/10) } \\
\hline & & & & $\mathrm{Ct}^{\mathrm{b}}$ & Recovery yields ${ }^{\mathrm{c}}$ & $\mathrm{Ct}^{\mathrm{b}}$ & Recovery yields ${ }^{c}$ \\
\hline \multirow[t]{4}{*}{ MSB } & MNV & $2.4 \times 10^{6}$ & 15 & $26.0 \pm 0.6$ & $2.8 \%(1.8-3.8)$ & $\mathrm{nt}$ & nt \\
\hline & GII.4 & $5 \times 10^{4}$ & 15 & $29.7 \pm 1.2$ & $2.6 \%(1.7-5.0)$ & $30.4 \pm 2.5$ & $6.2 \%(4.2-8.2)$ \\
\hline & GII.4 & $1.7 \times 10^{3}$ & 5 & $34.0 \pm 1.5$ & $5.7 \%(0.8-6.6)$ & $\mathrm{nt}$ & $\mathrm{nt}$ \\
\hline & GI.5 & $6 \times 10^{4}$ & 15 & $29.2 \pm 0.8$ & $3.6 \%(2.4-4.9)$ & $32.8 \pm 0.8$ & $3.0 \%(2.1-3.9)$ \\
\hline 15216 & GII.4 & $5 \times 10^{4}$ & 15 & $29.8 \pm 1.9$ & $1.8 \%(0.1-3.6)$ & $30.8 \pm 1.5$ & $9.3 \%(7.1-11.5)$ \\
\hline
\end{tabular}

$n$ extraction assay, $n t$ not tested, $C t$ cycle threshold, $M S B$ magnetic silica beads, 15216 ISO 15216-1:2017

${ }^{\mathrm{a}}$ Genomic equivalent copies

${ }^{\mathrm{b}}$ Average $\mathrm{Ct} \pm$ standard deviation

${ }^{\mathrm{c}}$ Geometric mean (95\% confidence interval) 
Table 3 Norovirus recovery yields from frozen raspberries in the presence of competition

\begin{tabular}{|c|c|c|c|c|c|c|c|}
\hline \multirow[t]{2}{*}{ Extraction method } & \multirow[t]{2}{*}{$n$} & \multicolumn{3}{|l|}{ Virus } & \multicolumn{3}{|c|}{ Competitor virus } \\
\hline & & Virus & Spiking level $^{\mathrm{a}}$ & Recovery yields ${ }^{b}$ & Virus & Spiking level $^{\mathrm{a}}$ & Recovery yields ${ }^{b}$ \\
\hline \multirow[t]{3}{*}{ MSB } & 5 & GII.4 & $3 \times 10^{5}$ & $4.5 \%(3.5-5.8)$ & GI.5 & $10^{5}$ & $3.0 \%$ (2.0 to 5.0$)$ \\
\hline & 5 & GII.4 & $4 \times 10^{4}$ & $3.4 \%(1.8-6.2)$ & $\mathrm{nt}$ & $\mathrm{nt}$ & $\mathrm{nt}$ \\
\hline & 5 & $\mathrm{nt}$ & $\mathrm{nt}$ & $\mathrm{nt}$ & GI.5 & $10^{5}$ & $1.8 \%(-0.4$ to 4.0$)$ \\
\hline
\end{tabular}

Raspberries spiked with or without competitor virus were extracted and tested by RT-qPCR

$n$ extraction assay, $n t$ not tested, $M S B$ magnetic silica beads

${ }^{\mathrm{a}}$ Genomic equivalent copies

${ }^{\mathrm{b}}$ Geometric mean (95\% confidence interval)

\section{RT-qPCR Inhibition}

The ratio of diluted (1/10) to non-diluted HuNoV GII RNA recovery yields indicated a fairly high relative RT-qPCR inhibition value of 5.2 when the HuNoV GII RNA was extracted from frozen raspberries using the ISO 152161:2017 method compared to a ratio value of 2.4 observed with the MSB method (Table 2). Ratio values above 4 represent more than $75 \%$ RT-qPCR inhibition. In contrast, the tenfold dilution of the HuNoV GI RNA from samples extracted using the MSB method on frozen raspberries had no impact on the recovery yields $(p=0.214)$. The average undiluted HuNoV GI RNA extract $\mathrm{Ct}$ was not lower than the diluted ones after correction for the dilution factor.

Using the HuNoV GII and GI RNA transcripts with insert as EAC, a statistically significant impact of the RT-qPCR kit $(p<0.001)$ on the RT-qPCR inhibition was observed (Fig. 2). The average RNA UltraSense HuNoV GII RT-qPCR inhibition percentages measured using the RNA extracted with the ISO 15216-1:2017 and the MSB approaches were 58\% (95\% CI 32-83) ( $n=12$ replicates) and $56 \%$ (95\% CI 41-71) $(n=20)$, respectively. However, when testing the HuNoV GII EAC amplification using the TaqMan ${ }^{\circledR}$ Fast Virus 1-Step, the average RT-qPCR inhibition percentages calculated with the RNA extracts using the ISO 15216-1:2017, and the MSB protocols were decreased to $24 \%(95 \%$ CI $7-42)(n=12)$ and $1 \%(95 \%$ CI 7 to 9$)$ $(n=20)$, respectively. Similar EAC inhibition levels were observed using the HuNoV GI RT-qPCR. RT-qPCR inhibition values were above the $75 \%$ when tested with the RNA UltraSense kit for $46 \%$ and $25 \%$ of the RNA samples extracted with the ISO 15216-1:2017 and the MSB methods, respectively. There was no impact of the extraction method on the RT-qPCR inhibition $(p=0.110)$.

\section{Limit of Detection}

The limit of detection of the MSB method was evaluated by RT-qPCR using RNA extracted from frozen raspberries spiked with HuNoV GII.4 strain CFIA-FVR-019 (Supplementary Fig. SF1). Overall, 70 spiked and 14 non-spiked frozen raspberry samples were tested. The MSB RTqPCR $\mathrm{LOD}_{95}$ and $\mathrm{LOD}_{50}$ were $2370 \mathrm{gEq}$ per $25 \mathrm{~g}(95 \%$ CI 1542-3642) and $548 \mathrm{gEq}$ per $25 \mathrm{~g}$ (95\% CI 357-843), respectively.

\section{Discussion}

Frozen raspberries have been associated with several norovirus outbreaks and remain a challenging food matrix for virus detection. We have experienced some difficulties with the workflow of the ISO/TS 15216-1:2013. The limited pH range during elution, the impact of PCR inhibitors, and a tedious PEG pellet resuspension observed with frozen raspberry matrices make this method poorly adapted to testing the large number of samples CFIA diagnostic labs need to process every year $(>500)$. Some of these issues were resolved in the 2017 version of the method. As an alternative, we developed a new food virus extraction method based on magnetic silica beads (MSB) which was better adapted to our laboratory setting. The MSB approach to elute and concentrate norovirus from raspberries is based on a strategic use of electrostatic interactions at different steps of the protocol. The variations of the virus surface charge at different $\mathrm{pH}$ levels are illustrated in Fig. 1. According to the manufacturer, the fine magnetic silica beads have a small size $(420 \mathrm{~nm})$ and have a negative zeta potential in water $(-37 \mathrm{mV})$. On the other hand, silica particles are prone to aggregation in the presence of salts (Metin et al. 2011). In the MSB method, a non-ionic buffer (Bis-Tris-Propane) was used, and salts were avoided in the buffer solutions to reduce the ionic strength and to limit the aggregation of magnetic silica particles. The effect of $\mathrm{pH}$ and charge of the norovirus were also taken into account. According to Da Silva et al. (2011), HuNoV GI Virus-like particles (VLP) are prone to adhesion onto silica below the VLP isoelectric point whereas its attachment is reduced at higher $\mathrm{pH}$ at low salt concentrations.

It is difficult to compare method performance based on the literature or laboratory reports ( $\mathrm{Li}$ et al. 2018). In addition to the extraction protocols, variations in recovery 
Fig. 2 RT-qPCR inhibition percentages in frozen raspberry RNA extracts. A box plot of RT-qPCR inhibition evaluated using a HuNoV GI and b HuNoV GII external control RNA amplification is shown. The absence of RT-qPCR inhibition or enhancement should read as 0 . The error bars represent the $95 \%$ confidence intervals of the mean. The horizontal dotted line represents $75 \%$ inhibition

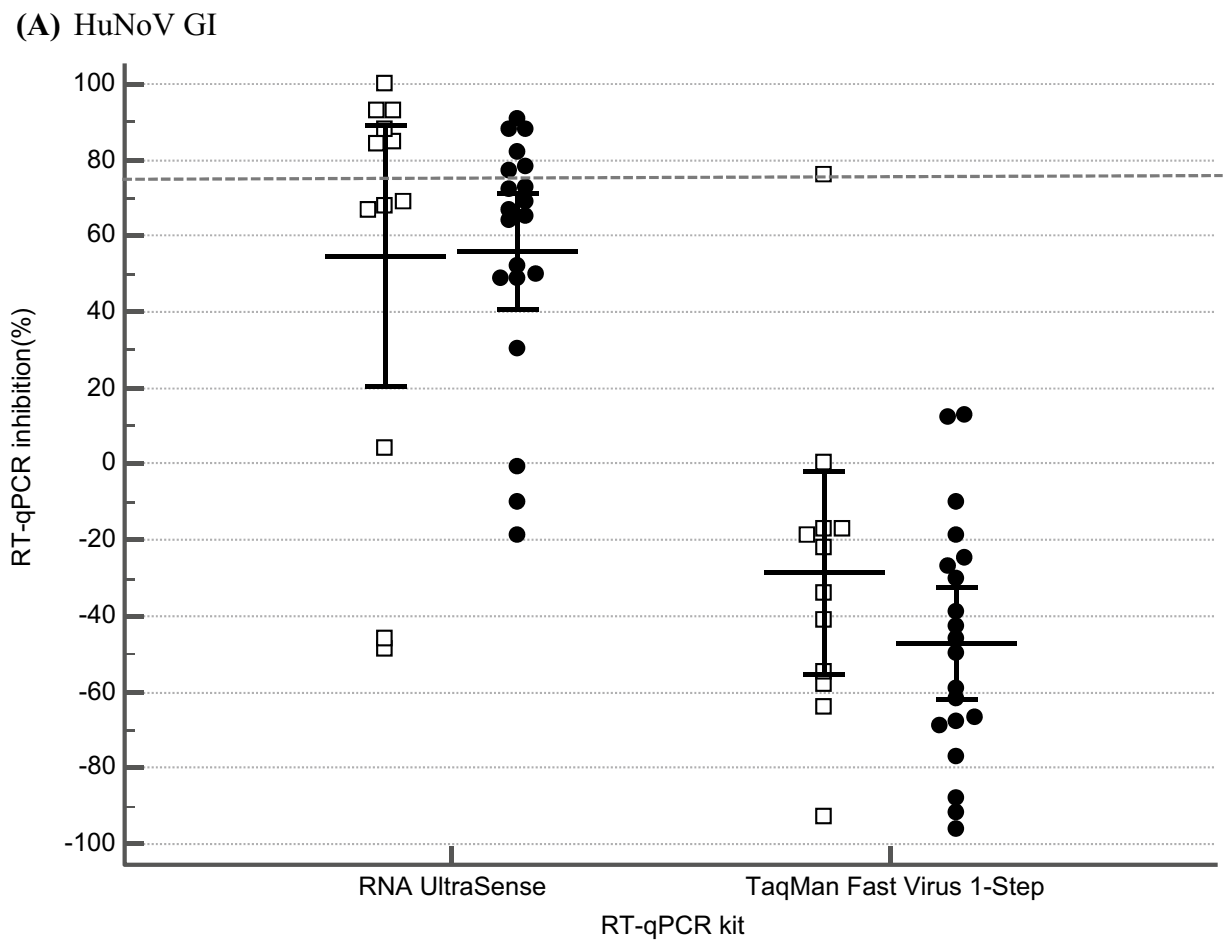

(B) HuNoV GII

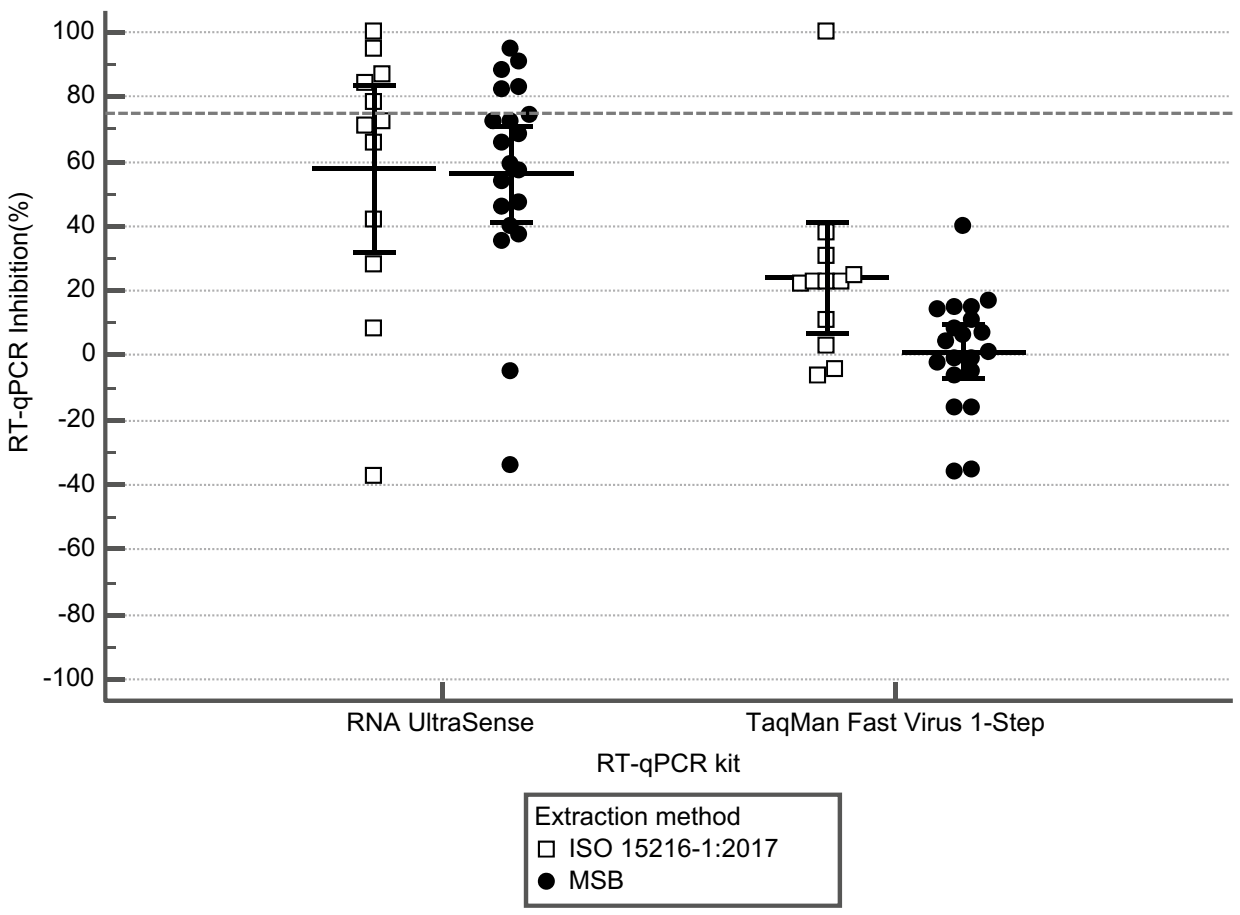

yields could be associated to the inoculated virus preparation, clarification, filtration, the virus strain, its integrity, as well as the spiking conditions. The method should be fit for its intended purpose and detects $\mathrm{HuNoV}$ in frozen raspberries at level equivalent to the $50 \%$ human infectious dose (HID50). The HID50 of the HuNoV in susceptible healthy adults varies with the serogroup. The HID50 of the HuNoV
Norwalk strain was estimated at 1320 (95\% CI 440-3760) genomic equivalent (gEq) in serogroups $\mathrm{O}$ and $\mathrm{A}$ (Atmar et al. 2014). The HuNoV GII LOD $_{95}$ reported in this study using the MSB approach was higher $\left(2 \times 10^{3}\right.$ vs. $0.7 \times 10^{3}$ $\mathrm{gEq}$ per $25 \mathrm{~g}$ ) than the ones reported by another study using the ISO 15216-1:2017 ( $\mathrm{Li}$ et al. 2018). On the other hand, recovery yields obtained for undiluted $\mathrm{HuNoV}$ GI and 
HuNoV GII using the MSB method were in the same range (2.6-5.7\%) as the ISO 15216-1:2017 reported by Fraisse et al. (2017). While achieving the lowest detection limit is a major goal of extraction methodologies, its application also influences method selection. For instance, methodologies that could discriminate between inactivated and infectious virus are required to avoid overestimating the viral infectivity. Viability RT-qPCR based on viral integrity treatment is a promising approach to improve risk assessment of positive RT-qPCR detection results (Chen et al. 2020). The integrity of the virus following its elution and concentration might varied between different viral RNA extraction methodologies and requires further investigation.

Raspberries contain high levels of heteropolysaccharides, such as pectin, which have a major impact on the viral extraction process. The pectin appears to form a strong gel with calcium at a pH close to 5 which interferes with the elution process (Han et al. 2017). Pectinase treatment, lower $\mathrm{pH}$, and low calcium conditions were required to avoid bead agglomeration when performing the MSB elution from frozen raspberries. The current low $\mathrm{pH}$ extraction process was effective with a limited set of matrices.

In addition to pectin, the extraction of $\mathrm{HuNoV}$ from frozen raspberries presented other challenges. Raspberries contain multiple components that are co-extracted with the viral genome and can impact its molecular detection. High levels of polyphenols (e.g., anthocyanin, flavonol, ellagitannin, proanthocyanidin, phenolic acids, tannic acid) can act as PCR inhibitors (reviewed in Schrader et al. (2012)). Heteropolysaccharides can disturb the RT and PCR enzymatic process by mimicking the structure of nucleic acids. Phenolic compounds may cross-link RNA under oxidizing conditions and could degrade DNA polymerases. To reduce the presence of PCR inhibitors, the MSB method includes a treatment with insoluble polyvinylpolypyrrolidone that was reported to prevent polyphenol oxidation and subsequent binding to nucleic acids when extracting total RNA from raspberries (Jones et al. 1997).

High levels of RT-qPCR inhibition have been reported by several groups that evaluated PEG-derived extraction methods including ISO/TS 15216-1:2013 and ISO 152161:2017 with frozen raspberries (De Keuckelaere et al. 2015; Fraisse et al. 2017; Summa and Maunula 2018; Summa et al. 2012). With frozen raspberries RNA extracted using the ISO 15216-1:2017, RT-qPCR inhibition was estimated at $93.8 \% \pm 2.5 \%$ using an external RNA control (Fraisse et al. 2017). According to the ISO 15216-1:2017, negative results obtained in presence of RT-qPCR inhibition levels $>75 \%$ are not valid.

Meanwhile in this study, close to $50 \%$ of the undiluted samples extracted following the ISO 15216-1:2017 protocol and tested using the RNA UltraSense detection kit presented more than $75 \%$ inhibition. Such a level of inconclusive assays increases the burden of testing and could double reported prevalence estimates if this factor was not taken into account. The ISO 15216-1:2017 recommends a larger elution volume ( $100 \mu \mathrm{l}$ vs $50 \mu \mathrm{l})$ and requires testing a tenfold diluted RNA extract as well as testing EAC to avoid this issue (ISO 2017). Previously, a European survey reported that positive frozen raspberries contaminated with $\mathrm{HuNoV}$ were only detected using tenfold diluted RNA when RNA was extracted with the ISO/TS 15216-1:2013 method (Loutreul et al. 2014). Dilution of the soft fruit RNA extract decreases the impact of PCR inhibitors in the RT-qPCR. However, RNA extract dilution also impacts the capacity to detect the virus present at trace levels (Fraisse et al. 2017). Until improvements are shown regarding the recovery yields, strategies that decrease the impact of PCR inhibitors from frozen raspberry RNA extracts should be encouraged.

Different PCR inhibitor removal kits or the use of digital PCR have improved the ISO 15216-1: 2017 recovery yields (Fraisse et al. 2017; Bartsch et al. 2016, 2018). For instance, an additional RNA purification step using either the MobiSpin column or the OneStep ${ }^{\circledR}$ PCR Inhibitor Removal Kit (Zymo research) were added with the ISO/TS 152161:2013 protocol to remove RT-PCR inhibitors from frozen strawberries and improve the detection limit (Bartsch et al. 2016, 2018). Alternative extraction approaches could also reduce the amount of RT-PCR inhibitors. With Bovine Norovirus spiked on frozen raspberries, Sun et al. (2019) have reported the absence of RT-PCR inhibition using a direct lysis approach combined with either RNA filtration using the MobiSpin column or digital PCR detection. The results in this study indicated that the RT-qPCR inhibition is also influenced by the selected detection method. The RNA UltraSense kit is described in the ISO 15216-2017 method, but it is not a requirement for the method. The RNA UltraSense kit might be suitable for some food matrices included in the scope of this method that are associated to low RT-qPCR inhibition. However, the TaqMan Fast Virus 1-Step results indicate that the UltraSense kit is not the most appropriate detection kit to test RNA extracted from frozen raspberries. The impact of PCR inhibitors from frozen raspberry RNA extracts on other commercial RT-qPCR kit was not explored. Commercial RT-qPCR kits use different proprietary buffers and additives to reduce the impact of PCR inhibitors. The extracted PCR inhibitors vary with the type of food matrix. Consequently, the impact of inhibitors on commercial RT-qPCR kits should be tested for each type of food matrix.

Several groups have used various forms of the ISO 15216 method to recover HuNov from frozen raspberries. The observed range of recovery yields from 1 to $6 \%$ range could certainly impact the reported prevalence. Nevertheless, Loutreul et al. (2014) reported a prevalence of $16.7 \%$ $(n=162)$ for HuNov GI in frozen raspberries from Serbia, Chile, Bulgaria, Poland, and France. In the UK, 3.6\% 
$(n=274)$ of frozen raspberry samples sold at retail were positive for HuNoV (Cook et al. 2019). However, this group was not able to differentiate the sequence of the $\mathrm{HuNoV}$ detected from their EAC. Gao et al. (2019) reported that $9.2 \%$ and $13 \%$ of frozen raspberries from Heilongiiang Province in China were positive to HuNoV in 2016 and 2017, respectively. Meanwhile, all export samples were negative. They used a replicate $\mathrm{Ct}$ threshold for positive results, which could lower prevalence estimate, and did not analyze the RT-qPCR inhibition level. Maunula et al. (2013) did not detect HuNov in frozen raspberry samples (0/39) from point of sale of four European countries, but did find some HuNov GII in irrigating water from berry production sites (2/56). They used high pectinase concentration and RNA extract elution volume $(300 \mu \mathrm{l})$ for berries but did not report any RT-qPCR inhibition. The true prevalence as well as the extraction method recovery yields and the presence of PCR inhibitors could play a role in resolving some of the discrepancies observed in terms of prevalence between those groups. Still, the contamination levels in some of these surveys remains relatively important from a risk analysis perspective.

\section{Conclusion}

A method based on magnetic silica beads to extract $\mathrm{HuNoV}$ virus RNA from frozen raspberries was developed. The MSB method performance was similar to the reference method ISO 15216-1:2017. The influence of RT-qPCR inhibitors extracted using both methods was reduced using an alternative RT-qPCR detection kit (TaqMan Fast Virus 1-Step Master Mix) and condition. In future, the reduction of the RT-qPCR inhibitors which impact the HuNoV detection results should reduce the number of inconclusive assays and influence prevalence estimates.

Supplementary Information The online version contains supplementary material available at https://doi.org/10.1007/s12560-021-09466-0.

Acknowledgements The authors acknowledge the work of analysts and scientist from the CFIA Food Virology National Reference Center (FVNRC) for the production of RNA transcript standards (MO, VL, YL). Names of specific vendors, manufacturers, or products are included for informational purposes only and do not imply endorsement by authors.

Author contributions Conceptualization: PR and LD. Funding acquisition: PR and LD. Supervision: PR, Methodology: PR, SP and AP. Data curation: PR and SP. Formal analysis: PR. Writing original draft: PR. Writing review \& editing: PR, AP, SP and LD.

Funding This work was supported by the Canadian Food Inspection Agency Research \& Partnership Strategy (STH-F-1306 and STH-F-1607).

\section{Compliance with Ethical Standards}

Conflict of interest The authors have no conflict of interest to declare.

Open Access This article is licensed under a Creative Commons Attribution 4.0 International License, which permits use, sharing, adaptation, distribution and reproduction in any medium or format, as long as you give appropriate credit to the original author(s) and the source, provide a link to the Creative Commons licence, and indicate if changes were made. The images or other third party material in this article are included in the article's Creative Commons licence, unless indicated otherwise in a credit line to the material. If material is not included in the article's Creative Commons licence and your intended use is not permitted by statutory regulation or exceeds the permitted use, you will need to obtain permission directly from the copyright holder. To view a copy of this licence, visit http://creativecommons.org/licenses/by/4.0/.

\section{References}

Andrade, A. L., Souza, D. M., Pereira, M. C., Fabris, J. D., \& Domingues, R. Z. (2009). Synthesis and characterization of magnetic nanoparticles coated with silica through a sol-gel approach. Cerâmica, 55, 420-424.

Atmar, R. L., Opekun, A. R., Gilger, M. A., Estes, M. K., Crawford, S. E., Neill, F. H., et al. (2014). Determination of the $50 \%$ human infectious dose for Norwalk virus. Journal of Infectious Diseases, 209(7), 1016-1022. https://doi.org/10.1093/infdis/jit620.

Baert, L., Wobus, C. E., Van Coillie, E., Thackray, L. B., Debevere, J., \& Uyttendaele, M. (2008). Detection of murine norovirus 1 by using plaque assay, transfection assay, and real-time reverse transcription-PCR before and after heat exposure. Applied and Environment Microbiology, 74(2), 543-546. https://doi.org/10.1128/ AEM.01039-07.

Bartsch, C., Hoper, D., Made, D., \& Johne, R. (2018). Analysis of frozen strawberries involved in a large norovirus gastroenteritis outbreak using next generation sequencing and digital PCR. Food Microbiology, 76, 390-395. https://doi.org/10.1016/j. fm.2018.06.019.

Bartsch, C., Szabo, K., Dinh-Thanh, M., Schrader, C., Trojnar, E., \& Johne, R. (2016). Comparison and optimization of detection methods for noroviruses in frozen strawberries containing different amounts of RT-PCR inhibitors. Food Microbiology, 60, 124-130. https://doi.org/10.1016/j.fm.2016.07.005.

Boqvist, S., Soderqvist, K., \& Vagsholm, I. (2018). Food safety challenges and one health within Europe. Acta Veterinaria Scandinavica, 60(1), 1. https://doi.org/10.1186/s13028-017-0355-3.

Bozkurt, H., Phan-Thien, K. Y., van Ogtrop, F., Bell, T., \& McConchie, R. (2020). Outbreaks, occurrence, and control of norovirus and hepatitis a virus contamination in berries: A review. Critical Reviews in Food Science and Nutrition. https://doi. org/10.1080/10408398.2020.1719383.

Brinkman, N. E., Haffler, T. D., Cashdollar, J. L., \& Rhodes, E. R. (2013). Evaluation of methods using celite to concentrate norovirus, adenovirus and enterovirus from wastewater. Journal of Virological Methods, 193(1), 140-146. https://doi.org/10.1016/j. jviromet.2013.05.014.

Chen, J., Wua, X., Sánchezb, G., \& Randazzob, W. (2020). Viability RT-qPCR to detect potentially infectious enteric viruses on heat processed berries. Food Control, 107, 106818. https://doi. org/10.1016/j.foodcont.2019.106818.

Chhabra, P., de Graaf, M., Parra, G. I., Chan, M. C., Green, K., Martella, V., et al. (2019). Updated classification of norovirus 
genogroups and genotypes. Journal of General Virology, 100(10), 1393-1406. https://doi.org/10.1099/jgv.0.001318.

Cook, N., Knight, A., \& Richards, G. P. (2016). Persistence and elimination of human norovirus in food and on food contact surfaces: A critical review. Journal of Food Protection, 79(7), 1273-1294. https://doi.org/10.4315/0362-028X.JFP-15-570.

Cook, N., Williams, L., \& D'Agostino, M. (2019). Prevalence of norovirus in produce sold at retail in the United Kingdom. Food Microbiology, 79, 85-89. https://doi.org/10.1016/j.fm.2018.12.003.

Da Silva, A. K., Kavanagh, O. V., Estes, M. K., \& Elimelech, M. (2011). Adsorption and aggregation properties of norovirus GI and GII virus-like particles demonstrate differing responses to solution chemistry. Environmental Science and Technology, 45(2), 520-526. https://doi.org/10.1021/es102368d.

Da Silva, A. K., Le Saux, J. C., Parnaudeau, S., Pommepuy, M., Elimelech, M., \& Le Guyader, F. S. (2007). Evaluation of removal of noroviruses during wastewater treatment, using real-time reverse transcription-PCR: Different behaviors of genogroups I and II. Applied and Environmental Microbiology, 73(24), 7891-7897. https://doi.org/10.1128/AEM.01428-07.

De Keuckelaere, A., Li, D., Deliens, B., Stals, A., \& Uyttendaele, M. (2015). Batch testing for noroviruses in frozen raspberries. International Journal of Food Microbiology, 192, 43-50. https://doi. org/10.1016/j.ijfoodmicro.2014.09.024.

Fraisse, A., Coudray-Meunier, C., Martin-Latil, S., HennechartCollette, C., Delannoy, S., Fach, P., et al. (2017). Digital RT-PCR method for hepatitis A virus and norovirus quantification in soft berries. International Journal of Food Microbiology, 243, 36-45. https://doi.org/10.1016/j.ijfoodmicro.2016.11.022.

Gao, X., Wang, Z., Wang, Y., Liu, Z., Guan, X., Ma, Y., et al. (2019). Surveillance of norovirus contamination in commercial fresh/frozen berries from Heilongjiang Province, China, using a TaqMan real-time RT-PCR assay. Food Microbiology, 82, 119-126. https ://doi.org/10.1016/j.fm.2019.01.017.

Gonzalez-Hernandez, M. B., Bragazzi Cunha, J., \& Wobus, C. E. (2012). Plaque assay for murine norovirus. Journal of Visualized Experiments, 66, e4297. https://doi.org/10.3791/4297.

Government of Canada. (2018). National enteric surveillance program annual summary 2017. Guelph: Public Health Agency of Canada.

Han, W., Meng, Y., Hu, C., Dong, G., Qu, Y., Deng, H., et al. (2017). Mathematical model of $\mathrm{Ca} 2+$ concentration, $\mathrm{pH}$, pectin concentration and soluble solids (sucrose) on the gelation of low methoxyl pectin. Food Hydrocolloids, 66, 37-48. https://doi. org/10.1016/j.foodhyd.2016.12.011.

Hoehne, M., \& Schreier, E. (2006). Detection of Norovirus genogroup I and II by multiplex real-time RT-PCR using a 3'-minor groove binder-DNA probe. BMC Infectious Diseases, 6, 69. https://doi. org/10.1186/1471-2334-6-69.

Houde, A., Leblanc, D., Poitras, E., Ward, P., Brassard, J., Simard, C., et al. (2006). Comparative evaluation of RT-PCR, nucleic acid sequence-based amplification (NASBA) and real-time RT-PCR for detection of noroviruses in faecal material. Journal of Virological Methods, 135(2), 163-172. https://doi.org/10.1016/j.jviro met.2006.03.001.

ISO. (2017). Horizontal method for determination of Hepatitis A virus and norovirus using real-time RT-PCR-Part 1: Method for quantification. In Microbiology of the food chain (Vol ISO 152161:2017). Geneva: International Organization for Standardization.

Jones, C. S., Iannetta, P. P., Woodhead, M., Davies, H. V., McNicol, R. J., \& Taylor, M. A. (1997). The isolation of RNA from raspberry (Rubus idaeus) fruit. Molecular Biotechnology, 8(3), 219-221. https://doi.org/10.1007/BF02760775.

Júnior, J. A. A., \& Baldo, J. B. (2014). The behavior of zeta potential of silica suspensions. New Journal of Glass and Ceramics, 4, 29-37. https://doi.org/10.4236/njgc.2014.42004.
Kageyama, T., Kojima, S., Shinohara, M., Uchida, K., Fukushi, S., Hoshino, F. B., et al. (2003). Broadly reactive and highly sensitive assay for Norwalk-like viruses based on real-time quantitative reverse transcription-PCR. Journal of Clinical Microbiology, 41(4), 1548-1557. https://doi.org/10.1128/ jcm.41.4.1548-1557.2003.

Kojima, S., Kageyama, T., Fukushi, S., Hoshino, F. B., Shinohara, M., Uchida, K., et al. (2002). Genogroup-specific PCR primers for detection of Norwalk-like viruses. Journal of Virological Methods, 100(1-2), 107-114.

Li, D., Butot, S., Zuber, S., \& Uyttendaele, M. (2018). Monitoring of foodborne viruses in berries and considerations on the use of RTPCR methods in surveillance. Food Control, 89, 235-240. https ://doi.org/10.1016/j.foodcont.2018.02.024.

Loisy, F., Atmar, R. L., Guillon, P., Le Cann, P., Pommepuy, M., \& Le Guyader, F. S. (2005). Real-time RT-PCR for norovirus screening in shellfish. Journal of Virological Methods, 123(1), 1-7. https:// doi.org/10.1016/j.jviromet.2004.08.023.

Loutreul, J., Cazeaux, C., Levert, D., Nicolas, A., Vautier, S., Le Sauvage, A. L., et al. (2014). Prevalence of human noroviruses in frozen marketed shellfish, red fruits and fresh vegetables. Food Environmental Virology, 6(3), 157-168. https://doi.org/10.1007/ s12560-014-9150-8.

Maunula, L., Kaupke, A., Vasickova, P., Soderberg, K., Kozyra, I., Lazic, S., et al. (2013). Tracing enteric viruses in the European berry fruit supply chain. International Journal of Food Microbiology, 167(2), 177-185. https://doi.org/10.1016/j.ijfoodmicr o.2013.09.003.

Metin, C. O., Lake, L. W., Miranda, C. R., \& Nguyen, Q. P. (2011). Stability of aqueous silica nanoparticle dispersions. Journal of Nanoparticle Research, 13(2), 839-850. https://doi.org/10.1007/ s11051-010-0085-1.

Morales-Rayas, R., Wolffs, P. F., \& Griffiths, M. W. (2010). Simultaneous separation and detection of hepatitis A virus and norovirus in produce. International Journal of Food Microbiology, 139(1-2), 48-55. https://doi.org/10.1016/j.ijfoodmicro.2010.02.011.

Nasheri, N., Vester, A., \& Petronella, N. (2019). Foodborne viral outbreaks associated with frozen produce. Epidemiology and Infection, 147, e291. https://doi.org/10.1017/S0950268819001791.

Scherer, K., Johne, R., Schrader, C., Ellerbroek, L., Schulenburg, J., \& Klein, G. (2010). Comparison of two extraction methods for viruses in food and application in a norovirus gastroenteritis outbreak. Journal of Virological Methods, 169(1), 22-27. https://doi. org/10.1016/j.jviromet.2010.06.008.

Schrader, C., Schielke, A., Ellerbroek, L., \& Johne, R. (2012). PCR inhibitors-Occurrence, properties and removal. Journal of Applied Microbiology, 113(5), 1014-1026. https://doi.org/10.11 11/j.1365-2672.2012.05384.x.

Stals, A., Baert, L., Van Coillie, E., \& Uyttendaele, M. (2012). Extraction of food-borne viruses from food samples: A review. International Journal of Food Microbiology, 153(1-2), 1-9. https://doi. org/10.1016/j.ijfoodmicro.2011.10.014.

Summa, M., \& Maunula, L. (2018). Rapid detection of human norovirus in frozen raspberries. Food Environmental Virology, 10(1), 51-60. https://doi.org/10.1007/s12560-017-9321-5.

Summa, M., von Bonsdorff, C. H., \& Maunula, L. (2012). Evaluation of four virus recovery methods for detecting noroviruses on fresh lettuce, sliced ham, and frozen raspberries. Journal of Virological Methods, 183(2), 154-160. https://doi.org/10.1016/j.jviro met.2012.04.006.

Sun, B., Bosch, A., \& Myrmel, M. (2019). Extended direct lysis method for virus detection on berries including droplet digital RT-PCR or real time RT-PCR with reduced influence from inhibitors. Journal of Virological Methods, 271, 113638. https://doi. org/10.1016/j.jviromet.2019.04.004. 
Svraka, S., Duizer, E., Vennema, H., de Bruin, E., van der Veer, B., Dorresteijn, B., et al. (2007). Etiological role of viruses in outbreaks of acute gastroenteritis in The Netherlands from 1994 through 2005. Journal of Clinical Microbiology, 45(5), 13891394. https://doi.org/10.1128/JCM.02305-06.

Vinje, J. (2015). Advances in laboratory methods for detection and typing of norovirus. Journal of Clinical Microbiology, 53(2), 373-381. https://doi.org/10.1128/JCM.01535-14.
Wilrich, C., \& Wilrich, P. T. (2009). Estimation of the POD function and the LOD of a qualitative microbiological measurement method. Journal of AOAC International, 92(6), 1763-1772.

Publisher's Note Springer Nature remains neutral with regard to jurisdictional claims in published maps and institutional affiliations. 